\title{
AUTONOMIA NOS DIREITOS REPRODUTIVOS
}

\author{
AUTONOMY IN REPRODUCTIVE RIGHTS
}

Quize Rôla ${ }^{1}$

Resumo: O presente artigo versa sobre a limitação da autonomia privada na seara dos direitos reprodutivos, especialmente para as mulheres, indivíduos vulnerados. O entendimento desse artigo é favorecer a autonomia retirando a necessidade da outorga conjugal para a esterilização discutindo o tema através da autonomia privada, dignidade da pessoa humana e questões de gênero.

Palavras-chave: Direitos reprodutivos. Autonomia privada. Direitos das mulheres.

Abstract: This article deals with the limitation of private autonomy in the area of reprodutive rights, especially for women, vulnerable individuals. The meaning of this articles is to favor autonomy by removing the need for marital granting for sterilization by discussing the issue the issue through private autonomy, human dignity and gender issues.

Keywords: reproductive rights. Autonomy; Women rights.

\section{INTRODUÇÃO}

Ao longo dos anos as mulheres conseguiram invadir o mercado de trabalho, ainda que não tenha alcançado os mesmos postos dos homens, sofrendo preconceito e condições adversas para ascensão. Uma das questões que trazem impacto é a reprodução, as mulheres passam por longo tempo gestacional, adicionado ao período de cuidado da criança, ainda que a Constituição Federal de 1988 assegure proteção à gestante e à gestação. As mães continuam a ser as principais responsáveis pelo cuidado das crianças, em que pese o fato de que, na última década, apesar do influxo de mulheres na força de trabalho.

O presente trabalho tem como objetivo analisar e debater alguns pontos relacionados à lei 9.263/96 (Lei de planejamento familiar- LPP) no que concerne ao

\footnotetext{
${ }^{1}$ Bacharela em Direito na Faculdade de Direito da Universidade Federal da Bahia (UFBA), integrante do Grupo de Pesquisa Direito e Sexualidades (UFBA). E-mail: quizerola@hotmail.com
} 
direito à liberdade de não procriar através contracepção cirúrgica, discutindo a esterilização como uma das formas de exercício da liberdade. Discutir-se-á aqui o confronto aos institutos constitucionais por conta afronta a autonomia para homens e mulheres, mas principalmente as últimas que são vulneráveis sociais. Portanto, essa discussão é não só uma que discussão da autonomia e limitação da liberdade, mas também, uma questão de gênero, já que a lei supracitada atinge em maior grau às mulheres.

\section{AUTONOMIA PRIVADA E DIREITOS REPRODUTIVOS}

Autônomo é aquele indivíduo que está apto a gerir sua própria vida, valendo-se de suas próprias vontades e princípios essa qualidade de ter independência, tomar decisões gera a responsabilidade de avocar para si as consequências advindas dessa autossuficiência. Para Roxana Borges "autonomia privada relaciona-se ao poder atribuído pelo ordenamento jurídico ao indivíduo para que possa reger, com efeitos jurídicos, suas próprias relações." ${ }^{2}$

"A autonomia é o princípio da dignidade da natureza humana, enquanto ser racional e, a liberdade é a chave da autonomia da vontade"3. Para Requião4, liberdade e autonomia privada não possuem papéis diversos, uma vez que a "autonomia privada é um princípio derivado da liberdade em sentido amplo".

Direitos reprodutivos assegurados no Brasil faz parte de uma história recente que passou a integrar o direito constitucional, posto ter sido elencado no art. 226 da Carta Magna. Em1996 também entrou em vigor a Lei 9.263 que em seu art. $3^{\circ}$ aduz que "o planejamento familiar é parte integrante do conjunto de ações

\footnotetext{
2 BORGES, R. C. B. Direitos de personalidade e autonomia privada.2. ed. São Paulo: Editora Saraiva, 2009.

${ }^{3}$ HUPFFER. H.M. O princípio da autonomia na ética kantiana e sua recepção na obra direito e democracia de Jürgen Habermas. Disponível em: <http://www.anima-opet.com.br/pdf/anima5-Seleta-Externa/HaideMaria-Hupffer.pdf>. Acesso: 30 nov. 2019.

${ }^{4}$ REQUIÃO. M. Estatuto da pessoa com deficiência, incapacidades e interdição. Salvador: Editora Juspodivm, 2016.
} 
de atenção à mulher, ao homem ou ao casal, dentro de uma visão de atendimento global e integral à saúde".

Segundo Diniz ${ }^{5}$, há algumas tendências que se mantêm nos estudos à beira do leito com mulheres que abortaram: a maioria é católica, jovem, pobre e já com filhos", isso demonstra que o aborto como ato tão condenado pela sociedade brasileiras tem múltiplas causas e facilitar o acesso à esterilização voluntária pode também traduzir-se em redução da finalização da gestação por método cirúrgico. Entretanto, a possibilidade de procedimento para não gerar filhos enfrenta grandes dificuldades, principalmente no sistema público de saúde, não só pelo excesso de contingente que seria preciso, em contraste com a alta demanda do Serviço Único de Saúde (SUS), mas também porque há legislação que cria óbice para o indivíduo que deseja realizar.

A Lei Federal 9.263/96 regula o $\S 7^{0}$ do art. 226 da Constituição Federal, que trata do planejamento familiar, com fito de garantir direitos iguais de constituição, limitação ou aumento da prole pela mulher, pelo homem ou pelo casal. Em uma pesquisa realizada numa unidade de saúde pública de Belo Horizonte, que reflete as proporções no Brasil, constatou-se que há "predominância de mulheres nos grupos, com demanda maciça pelos métodos contraceptivos" ${ }^{6}$, desde a implantação do programa de planejamento familiar.

Nesse estudo é demonstrado que a ausência dos homens é revelada e os relatos das participantes explicitam que a participação no programa serve para auxiliar na escolha que na maioria das vezes se relaciona "aos valores e modos de vida da população, ao domínio precário de informações para operá-los, bem como à provisão dos recursos pelo sistema municipal de saúde"7.

A lei de planejamento familiar, em que pese em seu texto estar disposto uma suposta igualdade de gênero, por questões culturais, o peso sobre o

\footnotetext{
${ }^{5}$ DINIZ.D. Aborto e saúde pública no Brasil. Cad. Saúde Publica 2007; 23(9):1992-1993. Disponível em: http://www.scielo.br/scielo.php?script=sci issuetoc\&pid=0102-311X20070009\&lng=pt\&nrm=iso. Acesso em 01 dez. 2019.

6 MOREIRA. M. H.C. ARAÚJO.J.N.G. de. Planejamento familiar: autonomia ou encargo feminino? Psicologia em Estudo, Maringá, v. 9, n. 3, p. 389-398, set./dez. 2004

7 Idem
} 
planejamento familiar ainda se mantém sobre as mulheres, e nas situações em que a gravidez sobrevém, a sua manutenção ou quando ocorre o aborto são situações em que as mulheres são marginalizadas. Sendo assim, a legislação supracitada que em seu art. 150 tipifica como crime passar por laqueadura ou vasectomia sem o preenchimento de alguns requisitos, assim como o aborto é um crime que marginaliza as mulheres, no caso da esterilização, esta não é única possível agente na redação da lei, entretanto, na prática, por questões socioculturais, torna-se o único alvo.

O texto normativo despreza os direitos fundamentais, contraria tratados internacionais firmados pelo Brasil e diverge dos principais ordenamentos jurídicos estrangeiros. $O$ artigo $10^{\circ}$ da norma supracitada no inciso I e $\S 5^{\circ}$ fere demasiadamente a autonomia do indivíduo e em especial das mulheres.

No dispositivo permite-se a esterilização voluntária unicamente "em homens e mulheres com capacidade civil plena e maiores de vinte e cinco anos de idade ou, pelo menos, com dois filhos vivos" ${ }^{\text {, }}$, neste caso deve ser observado "o prazo mínimo de sessenta dias entre a manifestação da vontade e o ato cirúrgico, período no qual será propiciado à pessoa interessada acesso a serviço de regulação da fecundidade" ${ }^{\text {, }}$, no quinto parágrafo ainda ressalta-se que na vigência de sociedade conjugal, a esterilização depende do consentimento expresso de ambos os cônjuges.

\section{CONTRACEPÇÃO CIRÚRGICA E DIGNIDADE HUMANA}

A esterilização humana artificial, segundo Clarrisa Bottega "pode ser realizada através de mecanismos que retirem as funções das trompas de Falópio

\footnotetext{
${ }^{8}$ BRASIL. LEI № 9.263, DE 12 DE JANEIRO DE 1996.Regula o § 70 do art. 226 da Constituição Federal, que trata do planejamento familiar, estabelece penalidades e dá outras providências, RJ, jan. 1996. Disponível em:<http://www.planalto.gov.br/ccivil_03/leis//9263.htm> Acesso em: 30 nov. 2019

${ }^{9}$ Idem
} 
nas mulheres ou ainda que retirem as funções dos canais seminais nos homens" ${ }^{\prime \prime}$, apontando para os procedimentos "conhecidos como vasectomia para homens e ligadura de trompas para mulheres"11.

Durante muitos anos o procedimento supramencionado aconteceu de modo clandestino, uma vez que, seguindo o que prescreve o artigo 129, §2ㄴ, III, do Código Penal, "lesão corporal de natureza grave, que resulte em debilidade permanente de membro, sentido ou função do corpo"12 é considerada como crime, dessa forma, até a promulgação da Constituição Federal era considerado ato tipificado.

A partir de 1988 e mais recentemente com a lei de planejamento familiar, o tema saiu da marginalidade, podendo ser realizado não apenas no sistema de saúde particular como também no serviço público, tendo regras específicas para sua realização, sendo certo que que no corpo da lei fica claro que deve ser desestimulado precocemente, ainda que esta seja uma condição relacionada com direitos da personalidade.

Nesse sentido, esclarece Laura Mattar: "Os direitos reprodutivos referemse, ao direito de decidir livre e responsavelmente sobre o número, o espaçamento e a oportunidade de ter filhos"13, além disso, "o direito a ter acesso à informação e aos meios para a tomada desta decisão"14.

A dignidade humana é um dos fundamentos da nossa Constituição Federal e está protegida por ela, reconhecida sua existência e eminência, é valor supremo da ordem jurídica. Com efeito, a dignidade da pessoa humana é reconhecida em nossa Constituição como princípio fundamental e norteador de todo o sistema

\footnotetext{
${ }^{10}$ BOTEGGA, Clarissa. LIBERDADE DE NÃO PROCRIAR E ESTERILIZAÇÃO HUMANA. Disponível em: <http://www.clarissabottega.com/Arquivos/Artigos/Revista Jur v 9 n 2 jul dez 2007 p 43 64.pdf> Acesso em: 01 dez. 2019.

11 Idem

12 BRASIL. Código Penal. Decreto-lei no 2.848, de 7 de dezembro de 1940. <http://www.planalto.gov.br/ccivil_03/decreto-lei/del2848compilado.htm> Acesso em 30 nov. 2019.

${ }^{13}$ MATTAR, Laura Davis. Reconhecimento jurídico dos direitos sexuais: uma análise comparativa com os direitos reprodutivos. Sur, Rev. int. direitos human., São Paulo, v. 5, n. 8, p. 60-83, June 2008. Available from $<$ http://www.scielo.br/scielo.php?script=sci_arttext\&pid=S1806-64452008000100004\&lng=en\&nrm=iso>. access on 05 Dec. 2019. http://dx.doi.org/10.1590/S1806-64452008000100004.

${ }^{14}$ Idem
} 
jurídico, político e social do país. Os direitos reprodutivos constituem uma faceta dos direitos sexuais esse é tutelado pela Magna Carta, como os direitos elencados voltados para as gestantes, e a gestação, (art. $6^{\circ}$ ), mesmo quando a gestante se encontra em cumprimento de pena (art. $5^{\circ}, \mathrm{L}$ ), e o direito ao "planejamento familiar"

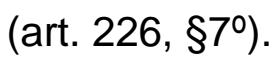

Ademais se o caput do artigo 226 da Constituição admite que a família é a base da sociedade e tem especial proteção do Estado, mereceria atenção também a família que deseja não ter prole, uma vez que o conceito atual de família, também se estende aos casais sem filhos independente da orientação sexual.

"Só a liberdade permite uma existência humana num mundo humano. A liberdade só possui significado na ação, na capacidade do homem de agir para tornar-se digno da felicidade"15. A realização dos direitos fundamentais, liberdade e dignidade fazem parte da formação do "mínimo existencial". ${ }^{16}$

O artigo 13 do Código Civil pátrio infere que "salvo por exigência médica, é defeso 0 ato de disposição do próprio corpo, quando importar diminuição permanente da integridade física, ou contrariar os bons costumes"17, ou seja, o indivíduo tem limitado seu direito de dispor do próprio corpo, entretanto, a lei de planejamento familiar determina que para concretizar o direito à disposição do corpo, terceiro, o cônjuge, tenha fundamental importância. “

\section{DIREITOS REPRODUTIVOS COMO DIREITO DA PERSONALIDADE}

"A autonomia da vontade individual, reflexo direto da dignidade da pessoa humana, pressupõe que decisões personalíssimas"18, como são aquelas

\footnotetext{
${ }^{15}$ HUPFFER. H.M. O princípio da autonomia na ética kantiana e sua recepção na obra direito e democracia de Jürgen Habermas. Disponível em: <http://www.anima-opet.com.br/pdf/anima5-Seleta-Externa/HaideMaria-Hupffer.pdf>. Acesso: 30 nov. 2019.

${ }^{16}$ WEBER, Thadeu. A ideia de um "mínimo existencial" de J. Rawls. Kriterion, Belo Horizonte, v. 54, n. 127, p. 197-210, June 2013. Disponível em <http://www.scielo.br/scielo.php?script=sci_arttext\&pid=S0100512X2013000100011\&Ing=en\&nrm=iso>. Acesso em 05 Dez. 2019. .

17 < http://www.planalto.gov.br/ccivil_03/leis/2002//10406.htm> Acesso em 30 nov. 2019.

18 BRASIL. AÇÃO DIRETA DE INCONSTITUCIONALIDADE 5911.№ único 0067050-27.2018.1.00.0000.
} 
"que envolvem direitos reprodutivos, não podem sujeitar-se à anuência de terceiros, nem mesmo de um cônjuge" ${ }^{19}$. Os direitos da personalidade são personalíssimos e intransponíveis, embora em algumas circunstâncias a disponibilidade desses direitos seja a possibilidade do titular ter melhor fruição de outros benefícios, que é o caso dessa cirurgia que é uma lesão corporal mas permite concretização de distintas garantias ${ }^{20}$.

Embora a lei de planejamento familiar confira tratamento igual aos cônjuges no que se refere a outorga conjugal para a esterilização é notório que ainda hoje há desequilíbrio de poder entre gêneros, o que compromete a decisão da mulher. Com esse entendimento, a redação da Lei Federal 11.340 de 2006 no art. $7^{\circ}$, III, infere que é uma forma de violência sexual "impedir de usar qualquer método contraceptivo ou que a force ao matrimônio, à gravidez, ao aborto"21, ou seja, "que limite ou anule o exercício de seus direitos sexuais e reprodutivos". O legislador admite que há uma vulnerabilidade social e que não pode ser descartada.

Parece um contrassenso, uma sociedade que no inciso I do art. 10 da Lei 9.263/96 o limita o proprietário do direito personalíssimo a alguns critérios, inadequados sob o julgo do desenvolvido nesse texto, estabelece que terceiro disponha não só sobre o corpo, mas também, sobre seu desejo de constituir ou majorar sua família. Ou seja, o inciso II, da referida lei mitiga os direitos da personalidade que são intransmissíveis e irrenunciáveis, em face de outro que pode ser inclusive ser seu agressor.

Ainda com esse entendimento, cabe ressaltar que o primeiro inciso do artigo supracitado limita a autonomia do indivíduo, na sociedade como se estabelece no século XXI e os variados conceitos de família, não é possível

\footnotetext{
${ }^{19}$ BRASIL. AÇÃO DIRETA DE INCONSTITUCIONALIDADE 5911.№ único 0067050-27.2018.1.00.0000

${ }^{20}$ BORGES, R. C. B. Direitos de personalidade e autonomia privada.2. ed. São Paulo: Editora Saraiva, 2009.

${ }^{21}$ BRASIL. Lei no 11.340, de 7 de agosto de 2006. Cria mecanismos para coibir a violência doméstica e familiar contra a mulher, nos termos do § 8o do art. 226 da Constituição Federal, da Convenção sobre a Eliminação de Todas as Formas de Discriminação contra as Mulheres e da Convenção Interamericana para Prevenir, Punir e Erradicar a Violência contra a Mulher; dispõe sobre a criação dos Juizados de Violência Doméstica e Familiar contra a Mulher; altera o Código de Processo Penal, o Código Penal e a Lei de Execução Penal; e dá outras providências. DF, ago. 2006 <http://www.planalto.gov.br/ccivil_03/_ato2004-2006/2006/lei/l11340.htm > Acesso em 5 dez. 2019.
} 
conjecturar que o indivíduo seja obrigado a manter outros métodos contraceptivos, com maior risco de uma gestação indesejável.

\section{CONSIDERAÇÕES FINAIS}

O legislador na Lei 9.263/96 criou ao seu próprio arbítrio a idade de 25 anos para fixar como limite inferior para realizar o procedimento, tornando crime conforme prescreve o art. 15 do mesmo instrumento normativo. Criminalizar essa ação constitui uma violência de gênero, uma vez que, o grupo social atacado por essa lei é o mesmo que atinge a criminalização do aborto, traz para o âmbito criminal situações que estão no rol da saúde pública, além de no caso específico da Lei de planejamento familiar ser uma situação que está apenas no rol da intimidade.

Em 2018 um partido político arguiu a inconstitucionalidade do art. 10 da LPP e nessa construção jurídica traçando a trajetória das mulheres e a luta feminista e seus obstáculos na sociedade, desde o século XIX com o início dos métodos contraceptivos. Admitir que o indivíduo quer seja homem ou mulher dependa do cônjuge para definir a possibilidade de um procedimento cirúrgico no ambiente mais íntimo do ser humano, seu corpo, ambiente inviolável é ferir completamente a autonomia do indivíduo, é como retornar ao período anterior ao código civil atual em que a mulher era relativamente incapaz, equiparada aos menores e aos pródigos.

Em 1994, na Conferência Mundial sobre População e Desenvolvimento, convocada pela ONU foram iniciadas as discussões sobre o direito de decidir livremente e responsavelmente sobre o número, o espaçamento e a oportunidade de ter filhos; direito de ter acesso à informação e aos meios para decidir, surgindo a questão da liberdade positiva e negativa de procriação como resposta ao planejamento familiar livre. A discussão em torno da possibilidade de ter autonomia no planejamento familiar em nenhum momento confunde-se com a mitigação dos direitos de personalidade, uma vez que, há uma empatia quanto à impossibilidade de realizar o método contraceptivo através da histerectomia (retirada do útero) ou 
Revista Direito e Sexualidade

n. 1 (maio.2020)

ooforectomia (retirada dos ovários), uma vez que nesses casos há sim , a violação da integridade física para além da questão reprodutiva, com efeitos sobe a saúde da mulher.

Deve ser considerado que a norma discutida é recente em uma sociedade que se mantém em constante transformação e as discussões aqui enfrentadas devem ser colocadas com a devida fundamentação jurídica, bem como as inovações sociais para encontrar meios de favorecer àqueles que não conseguem ter acesso à meios de planejamento familiar por conta do óbice legislativo.

Possibilitar a concreta efetivação da plena autonomia do indivíduo, não mitigando-a frente ao cônjuge em nenhum momento fere direitos, de outro modo, consegue ampliar garantias, estabelecer limites de atuação de terceiros sobre o corpo. A autonomia é um componente da dignidade da pessoa humana, tendo mais funções que apenas a reprodutiva, o ser humano tem fim em si mesmo como admite a filosofia Kantiana.

\section{REFERÊNCIAS BIBLIOGRÁFICAS}

BRASIL. Código Civil. Lei oㅜ 10.406, 10 jan de 2002. Institui o Código Civil. Disponível em: <http://www.planalto.gov.br/ccivil_03/leis/2002//10406.htm>. Acesso em 30 nov. 2019.

BRASIL. Lei no 9.263, de 12 de janeiro de 1996. Regula o $\S 7^{\circ}$ do art. 226 da Constituição Federal, que trata do planejamento familiar, estabelece penalidades e dá outras providências, RJ, jan. 1996. Disponível em:<http://www.planalto.gov.br/ccivil_03/leis//9263.htm> Acesso em: 30 nov. 2019

BRASIL. Lei no 11.340, de 7 de agosto de 2006. Cria mecanismos para coibir a violência doméstica e familiar contra a mulher, nos termos do $\S 8$ do art. 226 da Constituição Federal, da Convenção sobre a Eliminação de Todas as Formas de Discriminação contra as Mulheres e da Convenção Interamericana para Prevenir, Punir e Erradicar a Violência contra a Mulher; dispõe sobre a criação dos Juizados de Violência Doméstica e Familiar contra a Mulher; altera o Código de Processo Penal, o Código Penal e a Lei de Execução Penal; e dá outras providências. DF, ago. $2006 \quad<$ http://www.planalto.gov.br/ccivil 03/ ato20042006/2006/lei/l11340.htm > Acesso em 5 dez. 2019. 
Revista Direito e Sexualidade n. 1 (maio.2020)

BRASIL. Código Penal. Decreto-lei no 2.848, de 7 de dezembro de 1940. $<$ http://www.planalto.gov.br/ccivil 03/decreto-lei/del2848compilado.htm> Acesso em 30 nov. 2019.

BORGES, R. C. B. Direitos de personalidade e autonomia privada.2. ed. São Paulo: Editora Saraiva, 2009.

BOTEGGA, Clarissa. Liberdade de não procriar e esterilização humana. Disponível em: <http://www.clarissabottega.com/Arquivos/Artigos/Revista_Jur_v_9_n_2_jul_dez_ 2007_p_43_64.pdf> Acesso em: 01 dez. 2019.

DINIZ.D. Aborto e saúde pública no Brasil. Cad. Saúde Publica 2007; 23(9):1992-1993. Disponível em: $<$ http://www.scielo.br/scielo.php?script=sci issuetoc\&pid=0102311X20070009\&lng=pt\&nrm=iso >. Acesso em 01 dez. 2019.

HUPFFER. H.M. O princípio da autonomia na ética kantiana e sua recepção na obra direito e democracia de Jürgen Habermas. Disponível em: $<$ http://www.anima-opet.com.br/pdf/anima5-Seleta-Externa/Haide-Maria-

Hupffer.pdf>. Acesso: 30 nov. 2019.

MATTAR, Laura Davis. Reconhecimento jurídico dos direitos sexuais: uma análise comparativa com os direitos reprodutivos. Sur, Rev. int. direitos human., São Paulo, v. 5, n. 8, p. 60-83, June 2008. Disponível em < http://www.scielo.br/scielo.php?script=sci arttext\&pid=S1806-

64452008000100004\&lng=en\&nrm=iso $>$. Acesso em $05 \mathrm{dez} .2019$.

MOREIRA. M. H.C. ARAÚJO.J.N.G. de. Planejamento familiar: autonomia ou encargo feminino? Psicologia em Estudo, Maringá, v. 9, n. 3, p. 389-398, set./dez. 2004

REQUIÃO. M. Estatuto da pessoa com deficiência, incapacidades e interdição. Salvador: Editora Juspodivm, 2016.

WEBER, Thadeu. A ideia de um "mínimo existencial" de J. Rawls. Kriterion, Belo Horizonte, v. 54, n. 127, p. 197-210, June 2013. Disponível em <http://www.scielo.br/scielo.php?script=sci_arttext\&pid=S0100-

512X2013000100011\&lng=en\&nrm=iso>. Acesso em 05 Dez. 2019. 